\title{
Care and principles in chest drainage models during the COVID-19 pandemic
}

\section{Cuidados e princípios nos modelos de drenagem torácica durante a pandemia pela COVID-19}

ElCIO ShiYoiti HiRANo, TCBC- SP' ${ }^{1}$ (iD.

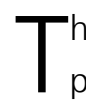
he article from Carvalho and Oliveira' covers an important topic in the COVID-19 pandemic scenario, which is chest drainage, as this procedure has the potential to generate aerosol, and it is performed in many environments, namely, intensive care units, wards, pre-hospital care, and emergency rooms. There is need to elaborate new procedures or adaptations due to the risk of contamination by the SARS-Cov-2 virus from aerosol or droplets'.

The most available method for chest drainage in the Brazilian Public Health System is the unidirectional water seal valve system (sterile water or saline solution), the connection remaining submerged around $2 \mathrm{~cm}^{2}$. However, an efficiency limiting factor is when there is a liquid flow, there is an increase in the water column inside the submerged connection, making it difficult for intrathoracic air or liquid to escape during the patient's breathing movements. Said article ${ }^{1}$ proposes a $5 \mathrm{~cm}$ of submersion of the connection in the water seal, which can increase the effort required for proper functioning.

The use of other liquid substances $(70 \%$ alcohol, sodium hypochlorite and others) ${ }^{3}$ to avoid contamination by aerosolization from bubbling from inside the chest drainage bottle into the environment raises doubts: When bubbling occurs due to air coming from the pleural space, does this liquid act on the particles suspended inside the bubbles before they burst? In addition, the liquids evaporate, therefore being able to either leave the environment through the vent or go into the intrapleural space through the connection, which can cause adverse reaction?

An adaptation to the method of thoracic drainage in water seal proposed by Carvalho and Oliveira ${ }^{1}$ is the use of filters. The High Efficiency Particulate Arrestance (HEPA) or Heat and moisture exchangers in combination with a bacterial and viral filter ( HMEF) are filters used in mechanical ventilators and must be replaced after a certain period of use. Aditionally, such devices impose resistance to airflow, which increases as they are accumulate moister ${ }^{4}$. To adapt the filter to the bottle vent, a connection was placed with a diameter smaller than the vent ${ }^{1}$, this being able to promote additional resistance. The use of these filters in a fashion similar to the one in ventilators, has the same principle of protection as the proposed method'; however, we must seek proper adjustments, so as not to decrease the effectiveness of chest drainage.

It is undeniable that in this period of the COVID-19 pandemic, studies and proposals are elaborated in all directions (prevention, pathophysiology, diagnosis and treatment), resulting in an intense information exchange.

Therefore, researches and proposals ${ }^{1}$ for new or adapted methods that aim to avoid or decrease the risk of contamination by SARS-CoV-2, so that they can be used, discussed, and adjusted. 


\section{REFERENCES}

1. Carvalho EA, Oliveira MVB. Safety model for chest drainage in pandemic by COVID-19. Rev Col Bras Cir. 2020;47:e20202568. Available from: https:// pubmed.ncbi.nlm.nih.gov/32490892

2. George RS, Papagiannopoulos K. Advances in chest drain management in thoracic disease. J Thorac Dis. 2016;8(Supp1):S55-S64. Available from: https://dx.doi.org/10.3978\%2Fj.issn.20721439.2015.11.19

Received in: 20/07/2020

Accepted for publication: 05/08/2020

Conflict of interest: no.

Funding source: none.
3. Kumar N, Kumar A, Kumar A, Kumar S. Coronavirus Disease-2019: Modified underwater seal chest drain system. J Cardiothorac Vasc Anesth. 2020;S10530770(20)30496-1. Available from: https://dx.doi. org/10.1053\%2Fj.jvca.2020.05.034

4. Morgan-Hughes NJ, Mills GH, Northwood D. Air flow resistance of three heat and moisture exchanging filter designs under wet conditions: implications for patient safety. Br J Anaesth. 2001;87(2):28991. Available from: https://pubmed.ncbi.nlm.nih. gov/11493505

\section{Mailing address:}

Elcio Shiyoiti Hirano

E-mail: hiranoes@gmail.com

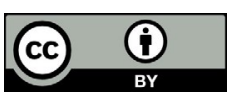

